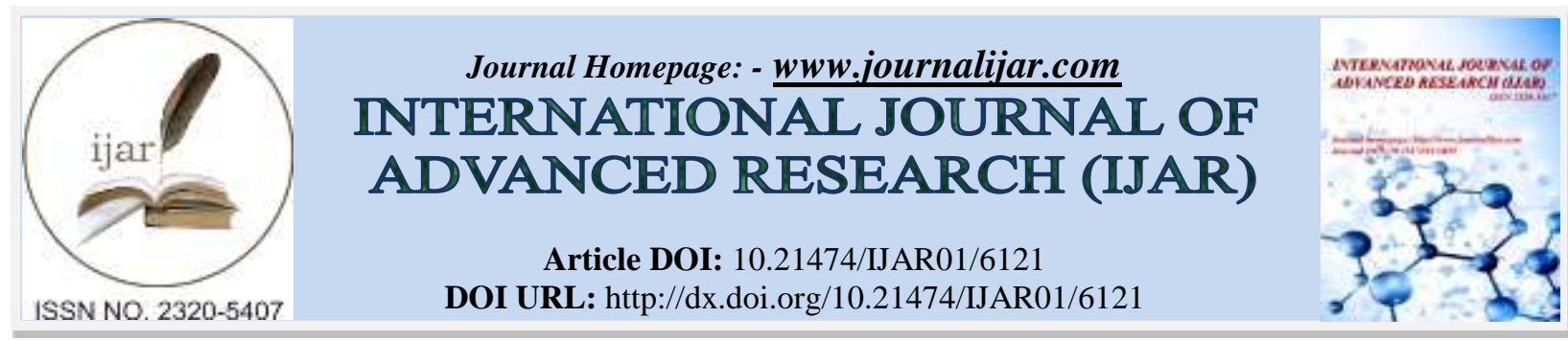

RESEARCH ARTICLE

\title{
EFFECT OF OOCYTE ACTIVATION WITH CALCIUM IONOPHORE ON ICSI OUTCOMES IN PATIENTS WITH PREVIOUS FERTILIZATION FAILURE.
}

Sherif Hebisha and Hesham M. Mahmoud.

M.D. Alexandria University faculty of Medicine.

\section{Manuscript Info}

Manuscript History

Received: 21 October 2017

Final Accepted: 23 November 2017

Published: December 2017

Keywords:-

Reproduction, ICSI, oocyte activation, fertilization.

\section{Abstract}

Background: Chemical activation is the most frequently used method for artificial oocyte activation (AOA), results in high fertilization rate.

Objective: To evaluate the efficiency of oocyte activation with calcium ionophore on fertilization and pregnancy outcomes after intracytoplasmic sperm injection (ICSI) in patients with previous fertilization failure.

Design: prospective controlled study

Materials and methods: One hundred and eight patients with history of previous fertilization failure undergoing IVF/ICSI treatment with long agonist protocol were randomly divided into two groups: group A $(n=54)$ and group B $(n=54)$; a total of 756 metaphase II (MII) oocytes were retrieved

In the oocytes of group $\mathrm{A}(\mathrm{n}=350$ oocyte), routine ICSI was applied; while in oocytes in group B ( $n=406$ oocyte) immediately after ICSI, were entered in culture medium supplemented with $5 \mu \mathrm{M}$ calcium ionophore (A23187) for 10 minutes and then washed at least five times with MOPS solution.

Main outcome measures: In both groups, the fertilization was evaluated after 16-18 hours.

Results: The number of fertilized oocytes and embryos obtained were significantly different between two groups $\left(\mathrm{p}=<0.001^{*}\right)$. Fertilization rate was significantly higher in group $\mathrm{B}$-where calcium ionophore was applied-compared to group $\mathrm{A}$ (control group) (32.2\% vs. 9.1\%, respectively , $\left.\mathrm{p}=0.01^{*}\right)$; and Cleavage rate also was significantly higher in group B compared to group A $(27.4 \%$ vs $12.5 \%$ respectively, $\mathrm{p}=0.028 *)$. Implantation rate was significantly higher in group B than in group A ( $18.32 \%$ vs. $3.12 \%$ respectively, $\left.\mathrm{p}=0.035^{*}\right)$ Pregnancy rate also was significantly higher in group B than in group A (22.2\% vs. $1.85 \%$ respectively, $\mathrm{p}=0.042 *)$.

Conclusion: Chemical oocyte activation with calcium ionophore resulted in a significant improvement in fertilization, cleavage, implantation and pregnancy rates after ICSI in infertile patients with previous fertilization failure. 


\section{Introduction:-}

The introduction of intracytoplasmic sperm injection (ICSI) in the early 1990s significantly improved the clinical outcome for infertile couples undergoing assisted reproductive techniques (ART), particularly those with low sperm counts who could not achieve normal levels of fertilization with conventional IVF. However, total fertilization failure (TFF) or low fertilization (LF) continues to be a major hindrance to a proportion of those cases undergoing ICSI. (Palermo et al 1992) TFF is seen in 1-4\%. (Liu et al., 1995, Esfandiari et al., 2005, Shinar et al., 2014)

Most cases of fertilization failure following ICSI can be traced back to a lack of oocyte activation, Yanagida K ( 2004) From the morphokinetic point of view, fertilization failure typically results from an insufficient number of mature, normal-morphology oocytes, irregular spermatozoon morphology, or poor motility characteristics. Yet, some patients with no such sperm defects and normal ovarian responses suffer from repeated fertilization failure. (Eldar-Geva et al., 2003)

On the intracellular level, the reason for this lack of oocyte activation may be a deficient cytosolic sperm-associated oocyte activating factor (SAOAF) resulting in a partial or complete inability of the sperm to activate the oocyte, (Dozortsev et al., 1995) or to an inability of the oocyte to decondense the sperm. (Schimiady et al., 1998)

The mature ovulated oocyte is arrested in metaphase of the second meiotic division (meiosis II) until fertilization by a sperm. Upon fertilization, spermatozoa overcome the second meiosis arrest by inducing a series of cellular events within the oocyte that are essential for normal development, and are collectively called oocyte activation. (BenYosef et al., 1998) These events include an early intercellular rise in calcium concentration from endoplasmic reticulum stores. This increase occurs 1 to 3 minutes after fusion of the sperm with oolemma, and it originates at the point of sperm entry. (Lawrence et al., 1997) (This initial increase occurs artificially with ICSI with the immediate influx of the calcium-containing media on sperm injection).

This first calcium transient rise is followed by a series of shorter calcium transient rises of high amplitude, which are known as calcium oscillations. As fertilization progresses, the amplitude and frequency of calcium oscillations decrease while their duration increases until absolute cessation after 2-3 hours. (McGuinness et al., 1996) Induction of calcium oscillations from intracellular stores in the human oocyte is believed to be triggered by inositol trisphosphate, which is catalyzed by sperm-specific phospholipase $\mathrm{C}$ named phospholipase $\mathrm{C}$ zeta1 (PLC $\zeta$ ), present in the perinuclear theca of sperm. (Young et al., 2008) The induced calcium oscillation leads to resumption of meiosis, decondensation of sperm nucleus, maternal RNA recruitment, formation of male and female pronuclei, initiation of DNA synthesis, and cleavage. (Yanagimachi et al., 1994)

Although abnormal PLC $\zeta$ deficiencies or mutations have been demonstrated as putative causes of failed activation, (Heytens et al., 2009) impaired oocyte responsiveness to PLC $\zeta$ and impaired oocyte-related generation and maintenance of calcium oscillations as a likely consequence of asynchrony between nuclear and cytoplasmic maturation may also be a factor. (Ajduk et al., 2008, Neri et al., 2014)

Assisted oocyte-activation (AOA) techniques-aiming at artificially increasing the intracellular calcium, whether mechanical, (Tesarik et al.,2002) electrical (Mansour et al., 2009) or chemical ( Hosseini et al., 2008) have been suggested as potential tools to overcome TFF but with variable success, lack of consistency in techniques and lack of long-term safety data for their use. Chemical stimulation - the most commonly used method for AOA - includes brief exposure of the injected oocytes to one of variable agents such as ethanol, strontium chloride, 6dimethylaminopurine, or calcium ionophores. Kline D et al., 1992, Yanagida et al., 2006)

\section{Materials And Methods:- \\ Patients:-}

This prospective randomized controlled trial was conducted at El-Shatby Maternity University hospital infertility unit in the period between January 2014 and March 2016.

During this period one hundred and eight patients with previous fertilization failure were included in the study. Informed consent was obtained from all patients before inclusion. Patients were randomly divided into two groups: group A (control group, $n=54$ ) and group $B$ (study group, $n=54$ ). 
Azospermic male partner or women with grade 3-4 endometriosis, uncorrected congenital uterine anomalies, or tubal pathology such as grade 3-4 endometriosis were excluded from the study.

\section{Ethical considerations:-}

Informed consent was obtained from all participants .

1. The study was approved by Alexandria University ethical committee.

2. The study was performed at Alexandria University, Egypt.

3. The authors have no conflict of interest.

\section{Stimulation protocol:-}

All cases underwent ICSI cycles using the long luteal agonist protocol in spontaneous or induced cycles. Pituitary down regulation was achieved using the GnRH agonist Decapeptyl (Tripterolin, Ferring). After suppression, controlled ovarian stimulation was performed using recombinant FSH/HMG (Gonal F, follitropin-alpha, Merck Serono) - (Merional, highly purified HMG IBSA). The starting dose was decided according to the AMH level and the AFC. Subsequent tailoring of the dose was done according to the individual response.

When at least three leading follicles reached $20 \mathrm{~mm}$ in the mean diameter, ovulation was triggered using $10000 \mathrm{IU}$ hCG (Choriomon, IBSA).

\section{Oocyte retrieval, Denudation, Sperm preparation and ICSI:-}

34-36 hours after hCG administration, oocyte retrieval was performed via transvaginal ultrasound guided aspiration. Standard oocyte denudation protocols using chemical followed by mechanical techniques were performed. Immature metaphase I or germinal vesicle stage oocytes were discarded and only mature metaphase II oocytes were injected. A total of 756 mature metaphase II (MII) oocytes were obtained. Group A had 350 M II oocytes while group B cases had 406 M II oocytes.

Semen was prepared by centrifugation on a density gradient or by the swim-up method, depending on the number of sperm collected after liquefaction. Oocytes were injected by ICSI within $2 \mathrm{~h}$ of oocyte denudation under 200x or 400x magnification. Each oocyte was positioned with its polar body at the 12 or 6 o'clock position, and subsequently, an injecting pipette containing immobilized spermatozoon was introduced at the 3 o'clock position with initial aspiration of the cytoplasm to ensure complete oolema penetration followed by injection of the sperm and withdrawal of the pipette.

\section{Oocyte culture and artificial oocyte activation:-}

All oocyte culture was performed in triple gas incubators at $37^{\circ} \mathrm{C}, 6 \% \mathrm{CO}_{2}$ and $5 \% \mathrm{O}_{2}$. Oocytes of group A cases (control group $\mathrm{n}=350$ ) were cultured as usual till the day of embryo transfer, whereas AOA was performed to the oocytes of group B (study group $\mathrm{n}=406$ ) by culture of the oocytes after ICSI in culture medium supplemented with $5 \mu$ calcium ionophore (A23187) for 10 minutes. After the 10 minute period, the oocytes were thoroughly washed in MOPS solution and then cultured as those of group A. Checking for fertilization was performed 16-18 hours later.

\section{Embryo Transfer and Luteal Support:-}

Embryo transfer was performed on day 3 or day 5 after injection according to the number and quality of embryos available in each case. Embryo transfer was performed under abdominal ultrasound guidance after performing a dummy embryo transfer.

Luteal support was given to all cases that underwent embryo transfer using vaginal progesterone (Cycolgest, Actavis) in a dose of $600 \mu \mathrm{g}$ daily and all cases were asked to perform a quantitative $\beta$ hCG test 16 days after the day of oocyte retrieval.

\section{Results:-}

As regards the age of cases included in the study, there was no statistically significant difference between both groups $(28.57 \pm 3.38$ vs $31.4 \pm 4.6, \mathrm{p}=0.243)$.

Also, both groups were statistically similar concerning the BMI ( $25.65 \pm 1.43$ vs $26.87 \pm 1.4, \mathrm{p}=0.744)$. (table 1$)$ As shown in ( table 2), The E2 and P4 levels on day of hCG, the AMH levels and the number of mature M2 oocytes retrieved did not differ significantly between both groups ( $2268.8 \pm 719.0$ vs $2818.7 \pm 1289.7, p=0.066,1.04 \pm 0.18$ vs $1.08 \pm 0.20$ 
$\mathrm{P}=0.176$, and $2.36 \pm 0.94$ vs $2.46 \pm 0.91 \mathrm{P}=0.754)$ respectively.

In this study, although the total number of mature M2 oocytes retrieved as well as the number of mature oocytes retrieved per case was not statistically significant between both groups $(\mathrm{p}=0.191)$ yet, the fertilization rate of oocytes per total number of mature oocytes injected was significantly higher in group B ( calcium ionophore group) (9.15\% vs $32.2 \% \mathrm{p}=0.01)$.

Again, the number of cleaved embryos and the rate of cleavage was significantly lower among the fertilized oocytes in group A compared to those in group B $\{4(12.5 \%)$ vs $36(27.48 \%) \mathrm{p}=0.028\}$.

Of the 4 cleaved embryos in group A, only 3 were suitable for transfer on the day of embryo transfer, whereas in group B, 34 embryos were transferred out of the 36 cleaved embryos. The transferred embryos were significantly more in group B than in group $\mathrm{A}(\mathrm{p}=0.021)$.

Moreover, the implantation rate and the pregnancy rate were significantly higher in the calcium ionophore group (18.32\% and $22.2 \%)$ than in the control group (3.12\% and $1.85 \%)(\mathrm{p}=0.035$ and $\mathrm{p}=0.042$ respectively). (table 3$)$ (fig 1)

Table (1):- Comparison between the two studied groups according to demographic data

\begin{tabular}{|c|c|c|c|c|}
\hline & $\begin{array}{l}\text { Group } \\
(n=54)\end{array} \quad$ A & $\begin{array}{l}\text { Group } \\
(n=54)\end{array}$ & $t$ & $\mathbf{P}$ \\
\hline $\begin{array}{l}\text { Age (years) } \\
\text { Min }- \text { Max } \\
\text { Mean } \pm \text { SD }\end{array}$ & $\begin{array}{l}19.0-39.0 \\
28.57 \pm 3.38\end{array}$ & $\begin{array}{l}20.0-38.0 \\
31.4 \pm 4.6\end{array}$ & 1.273 & 0.243 \\
\hline $\begin{array}{l}\text { BMI }\left(\mathbf{k g} / \mathbf{m}^{2}\right) \\
\text { Min - Max } \\
\text { Mean } \pm \text { SD }\end{array}$ & $\begin{array}{l}20.0-29.0 \\
25.65 \pm 1.43\end{array}$ & $\begin{array}{l}22.0-29.0 \\
26.87 \pm 1.4\end{array}$ & 0.313 & 0.744 \\
\hline
\end{tabular}

t: Student t-test

Table (2):- Comparison between the two studied groups according to serum E2, P4, AMH levels

\begin{tabular}{|c|c|c|c|c|}
\hline & $\begin{array}{ll}\text { Group } \\
(n=54)\end{array} \quad$ A & $\begin{array}{ll}\text { Group } & \text { B } \\
(\mathrm{n}=54) & \\
\end{array}$ & Test of sig & $\mathbf{p}$ \\
\hline $\begin{array}{l}\text { E2 } \\
\text { Min. - Max } \\
\text { Mean } \pm \text { SD }\end{array}$ & $\begin{array}{l}1100.0-4300.0 \\
2268.8 \pm 719.0\end{array}$ & $\begin{array}{l}800.0-5200.0 \\
2818.7 \pm 1289.7\end{array}$ & $Z=1.740$ & 0.066 \\
\hline $\begin{array}{l}\text { P4 } \\
\text { Min. - Max } \\
\text { Mean } \pm \text { SD }\end{array}$ & $\begin{array}{l}0.50-1.50 \\
1.04 \pm 0.18\end{array}$ & $\begin{array}{l}0.30-1.50 \\
1.08 \pm 0.20\end{array}$ & $\mathrm{t}=1.358$ & 0.176 \\
\hline $\begin{array}{l}\text { AMH } \\
\text { Min. - Max } \\
\text { Mean } \pm \text { SD }\end{array}$ & $\begin{array}{l}0.80-4.10 \\
2.36 \pm 0.94\end{array}$ & $\begin{array}{l}0.70-3.91 \\
2.46 \pm 0.91\end{array}$ & $\mathrm{Z}=0.313$ & 0.174 \\
\hline
\end{tabular}

Z: Z for Mann Whitney test

t: Student t-test

Table (3):- Comparison between the two studied groups according fertilization, cleavage, implantation and pregnancy rates:

\begin{tabular}{|l|l|l|l|l|}
\hline & $\begin{array}{l}\text { Group A } \\
\mathbf{n = 5 4}\end{array}$ & $\begin{array}{l}\text { Group B } \\
\mathbf{n = 5 4}\end{array}$ & Test of significance & P value \\
\hline M2 & & & & \\
Total number & 350 & 406 & & \\
Min. - Max & $3.0-22.0$ & $2.0-25.0$ & $\mathrm{Z}=1.218$ & \\
Mean \pm SD & $13.54 \pm 4.76$ & $12.84 \pm 5.67$ & & 0.191 \\
\hline Number of fertilized oocytes & 32 & 131 & $\mathrm{t}=4.018^{*}$ & \\
\hline Fertilization rate \% & $9.1 \%$ & $32.2 \%$ & & $0.028^{*}$ \\
\hline Number of cleaved embryos & 4 & 36 & $\mathrm{t}=2.372^{*}$ & \\
\hline
\end{tabular}




\begin{tabular}{|c|c|c|c|c|}
\hline Cleavage rate \% & $12.5 \%$ & $27.48 \%$ & & \\
\hline $\begin{array}{l}\text { Quality of embryos on day 3: } \\
<10 \% \text { fragmentation } \% \\
10-20 \% \text { fragmentation } \\
>\mathbf{2 0 - 5 0 \%} \text { fragmentation } \\
>\mathbf{5 0 \%} \text { fragmentaion }\end{array}$ & $\begin{array}{l}-- \\
-- \\
1(33.3 \%) \\
2(66.6 \%)\end{array}$ & $\begin{array}{l}5(14 \%) \\
15(44.1 \%) \\
8(23.5 \%) \\
6(17.6 \%)\end{array}$ & & \\
\hline $\begin{array}{l}\text { Number of day } 3 \text { embryos (6-8 } \\
\text { cells) }\end{array}$ & 3 & 34 & $\mathrm{t}=2.152$ & $0.021 *$ \\
\hline Implantation rate\% & $3.12 \%$ & $18.32 \%$ & & $0.035^{*}$ \\
\hline Pregnancy rate\% & $1.85 \%$ & $22.2 \%$ & & $0.042 *$ \\
\hline
\end{tabular}

Z: Z for Mann Whitney test

t: Student t-test

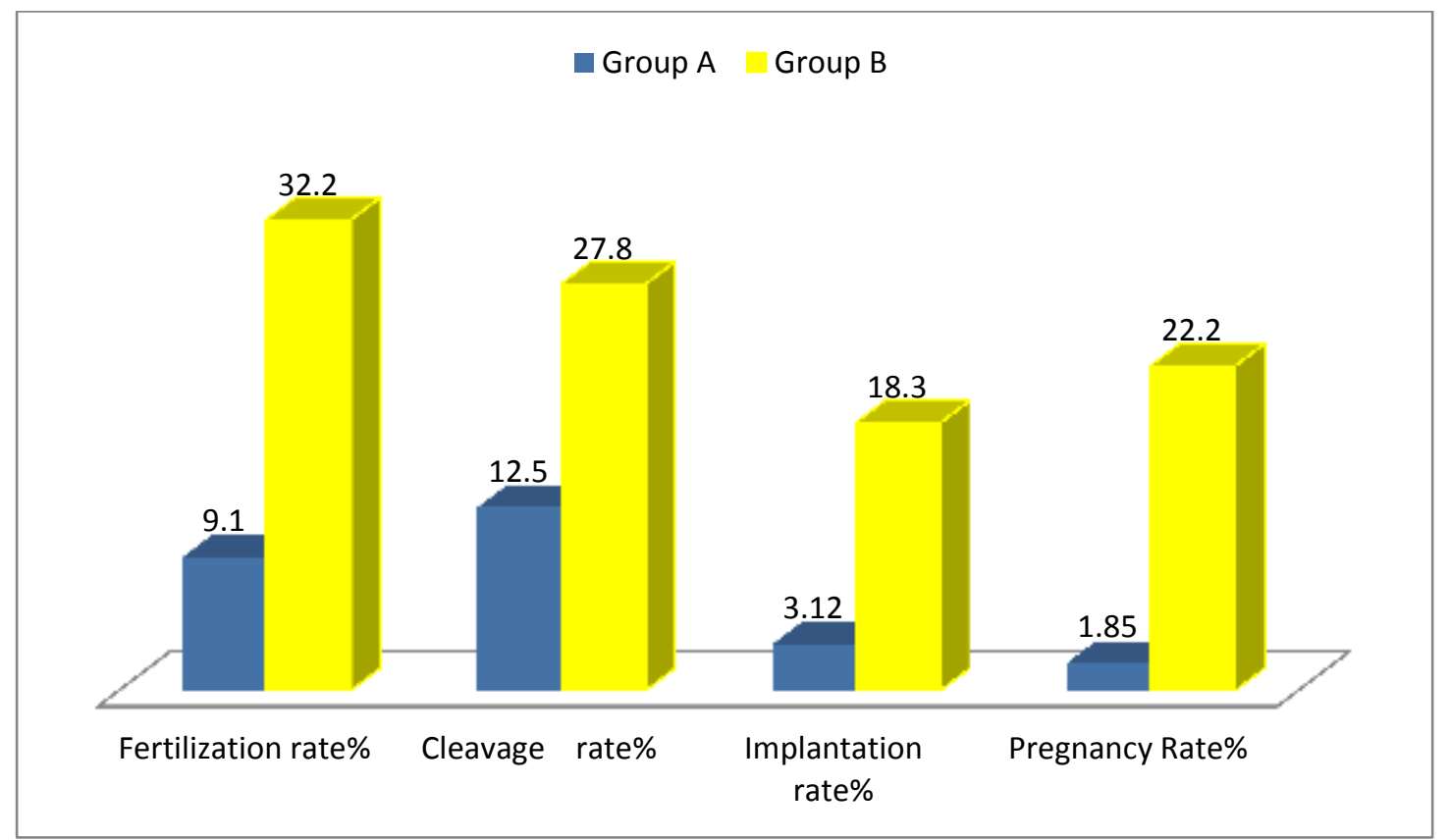

Figure 1:- Comparison between the two studied groups according fertilization, cleavage, implantation and pregnancy rate.

\section{Discussion:-}

Typical fertilization rates with ICSI average $70 \%$ for most patients, including those with poor sperm parameters or surgically retrieved sperm. (Capalbo et al., 2016) ${ }^{(22)}$

The term fertilization failure comprises two entities: Low fertilization, characterized by fertilization of less than $50 \%$ of injected mature oocytes which is seen in a considerable number of ICSI cycles and total fertilization failure that is seen in $1-4 \%$ of cycles. (Shinar et al., 2014)

Chromatin staining has implicated oocyte activation failure in $70 \%$ of cases of unfertilized oocytes, and half of post-ICSI fertilization failure cases have been attributed to low levels of sperm-derived oocyte activation factor. (Yanagida et al., 2008)

Of the different methods used for oocyte activation, chemical activation using calcium ionophore is the most commonly used one. Calcium ionophore is a lipid-soluble molecule that permits calcium transport across the cell membrane, transiently increasing cytoplasmic calcium levels, thereby enabling oocyte activation and fertilization. (Meerschaut et al., 2014) In this study we compared the use of calcium ionophore to non intervention in cases with 
previous fertilization failure. This study found significantly higher fertilization rate, cleavage rate, implantation rate as well as pregnancy rate in the activated oocytes group compared to the study group.

(Sdrigotti A et al., 2015) and (Yoon et al., 2013)' reported similar results in their studies. (Heindryckx et al., 2005) investigated the efficiency of AOA in improving the fertilization and the pregnancy rates in cases with no previous fertilization failure. Both (Yoon et al., 2013) and (Heindryckx et al., 2005) investigated AOA efficiency in male factor-derived infertility with different sperm origins. Results showed improved outcomes in all situations including poor ejaculate sperm and testicular derived sperm.

Contrary to the previous findings, (Ebner et al., 2015) found that AOA with calcium ionophore failed to improve the fertilization rates. Nonetheless, they found that exposure to calcium ionophore improved the number of embryo progression to blastocyst stage in cases with previous embryo development problems.

As regards the safety of oocyte activation using calcium ionophore, concerns have been raised that the sudden influx of calcium ions that does not mirror physiological changes may have a potential effect on gene expression and embryo development in animal models. (Ozil et al., 2006) Reassuringly, several studies have shown no difference as regards the chromosomal segregation errors, the congenital malformations as well as the neonatal and children development till the age of 10 years. (Lu et al., 2014)

\section{Conclusion:-}

AOA using calcium ionophore appears to be a promising method to overcome the problem of previous fertilization failure in ICSI with accepted safety. Further long term research is needed to assure the definite safety of the procedure before it can be used on a broader scale in ICSI cyles. For the time being, its use should be limited to cases with previous fertilization failure or cases with severe sperm abnormalities that warrants fear of fertilization failure.

\section{Acknowledgment:-}

Funding:- None

Conflict of interest:- None declared

Ethical approval: approved by ethical committee , Faculty of Medicine, Alexandria University.

\section{References:-}

1. Ajduk A, Małagocki A, Maleszewski M.(2008). Cytoplasmic maturation of mammalian oocytes: development of a mechanism responsible for sperm-induced Ca2+ oscillations. Reprod Biol. 8(1): 3-22.

2. Ben-Yosef D, Shalgi R.(1998). Early ionic events in activation of the mammalian egg. Rev Reprod. 3: 96-103.

3. Capalbo A, Ottolini CS, Griffin DK, Ubaldi FM, Handyside AH, Rienzi L.(2016) Artificial oocyte activation with calcium ionophore does not cause a widespread increase in chromosome segregation errors in the second meiotic division of the oocyte. Fertil Steril. 105: 807-14.

4. Dozortsev D, Rybouchkin A, De Sutter P, Qian C, Dhont M.(1995). Human oocyte activation following intracytoplasmic injection: the role of the sperm cell. Hum Reprod. 10: 403-7.

5. Ebner T, Oppelt P, Wöber M, Staples P, Mayer R, Sonnleitner U.(2015). Treatment with Ca2+ ionophore improves embryo development and outcome in cases with previous developmental problems: a prospective multicenter study. Hum Reprod. 30: 97-102.

6. Eldar-Geva T, Brooks B, Margalioth EJ, Zylber-Haran E, Gal M, Silber SJ.(2003). Successful pregnancy and delivery after calcium ionophore oocyte activation in a normozoospermic patient with previous repeated failed fertilization after intracytoplasmic sperm injection. Fertil Steril. 79: 1656-8.

7. Esfandiari N, Javed MH, Gotlieb L, Casper RF.(2005). Complete failed fertilization after intracytoplasmic sperm injection-analysis of 10 years' data. Int J Fertil Womens Med. 50: 187-92.

8. Heindryckx B, Van der Elst J, De Sutter P, Dhont M.(2005) Treatment option for sperm-or oocyte-related fertilization failure: assisted oocyte activation following diagnostic heterologous ICSI. Hum Reprod.20: 223741. 
9. Heytens E, Parrington J, Coward K, Young C, Lambrecht S, Yoon S-Y, et al.(2009) Reduced amounts and abnormal forms of phospholipase C zeta (PLCzeta) in spermatozoa from infertile men. Hum Reprod Oxf Engl. 24(10): 2417-28.

10. Hosseini SM, Hajian M, Moulavi F, Shahverdi AH, Nasr-Esfahani MH.(2008). Optimized combined electricalchemical parthenogenetic activation for in vitro matured bovine oocytes. Anim Reprod Sci. 108: $122-33$.

11. Kline D, Kline JT.(1992). Repetitive calcium transients and the role of calcium in exocytosis and cell cycle activation in the mouse egg. Dev Biol. 1992; 149: 80-9.

12. Lawrence Y, Whitaker M, Swann K.(1997). Sperm-egg fusion is the prelude to the initial $\mathrm{Ca}^{2+}$ increase at fertilization in the mouse. Development. 124: 233-41.

13. Liu J, Nagy Z, Joris H, Tournaye H, Smitz J, Camus M.(1995). Analysis of 76 total fertilization failure cycles out of 2732 intracytoplasmic sperm injection cycles. Hum Reprod. 10: 2630-6.

14. Lu Q, Chen X, Shen H, Zhang X, Li Y, Liyang R.(2014). No genetic alterations in infants from intracytoplasmic sperm injection in combination with artificial oocyte activation: a pilot study. Chin Med $\mathbf{J}$ (Engl). 127: 383-5.

15. Mansour R, Fahmy I, Tawab NA, Kamal A, El-Demery Y, Aboulghar M.(2009). Electrical activation of oocytes after intracytoplasmic sperm injection: a controlled randomized study. Fertil Steril. 1: 133-9.

16. McGuinness OM, Moreton RB, Johnson MH, Berridge MJ.(1996). A direct measurement of increased divalent cation influx in fertilised mouse oocytes. Development.122: 2199-206.

17. Meerschaut FV, Nikiforaki D, Heindryckx B, De Sutter P.(2014). Assisted oocyte activation following ICSI fertilization failure. Reprod Biomed Online. 28: 560-71.

18. Sdrigotti A, Rey Valzacchi GJ, Leocata Nieto FA, Canada VE.(2015). Artificial oocyte activation with calcium ionophore $(\mathrm{A}+23187)$ following ICSI fertilization failure. Fertil Steril.104: 302.

19. Neri QV, Lee B, Rosenwaks Z, Machaca K, Palermo GD.(2014). Understanding fertilization through intracytoplasmic sperm injection (ICSI). Cell Calcium. 55(1): 24-37.

20. Tesarik J, Rienzi L, Ubaldi F, Mendoza C, Greco E.(2002). Use of a modified intracytoplasmic sperm injection technique to overcome sperm-borne and oocyte-borne oocyte activation failures. Fertil Steril. 78(3): 619-24.

21. Ozil J-P, Banrezes B, Tóth S, Pan H, Schultz RM.(2006). Ca2+ oscillatory pattern in fertilized mouse eggs affects gene expression and development to term. Dev Biol. 300(2): 534-44.

22. Palermo G, Joris H, Devroey P, Van Steirteghem AC.(1992). Pregnancies after intracytoplasmic injection of single spermatozoon into an oocyte. Lancet. 340: 17-8.

23. Schimiady H, Tandler-Schneider A, Kentenich H.(1996). Premature chromosome condensation of the sperm nucleus after intra-cytoplasmic sperm injection. Hum Reprod. 11: 2239-45.

24. Shinar S, Almog B, Levin I, Shwartz T, Amit A, Hasson J.(2014). Total fertilization failure in intra-cytoplasmic sperm injection cycle -classification and management. Gynecol Endocrinol. 30:593-6.

25. Yanagida K.(2004). Complete fertilization failure in ICSI. Hum Cell. 17: 187-93.

26. Yanagimachi, R.(1994). Mammalian fertilization. in: E. Knobil, J. Neill (Eds.) The physiology of reproduction. 2nd ed. Raven Press, New York; 189-317.

27. Yanagida K, Fujikura Y, Katayose H.(2008). The present status of artificial oocyte activation in assisted reproductive technology. Reprod Med Biol. 7: 133-42.

28. Yanagida K, Morozumi K, Katayose H, Hayashi S, Sato A.(2006). Successful pregnancy after ICSI with strontium oocyte activation in low rates of fertilization. Reprod Biomed Online. 13: 801-6.

29. Yoon HJ, Bae IH, Kim HJ, Jang JM, Hur YS, Kim HK, Yoon SH, Lee WD, Lim JH.(2013). Analysis of clinical outcomes with respect to spermatozoan origin after artificial oocyte activation with a calcium ionophore. J Assist Reprod Genet. 30: 1569-75.

30. Young C, Grasa P, Coward K, Davis LC, Parrington J. (2008). Phospholipase C zeta undergoes dynamic changes in its pattern of localization in sperm during capacitation and the acrosome reaction. Fertil Steril. 91: $2230-42$. 